\title{
Monitoring Stasiun Pengisian Bahan Bakar Umum Berbasis Augmented-Reality
}

\author{
Cucun Very Angkoso, Wahedah, Koko Joni \\ Program Studi Teknik Informatika, Universitas Trunojoyo Madura \\ cucunvery@gmail.com
}

\begin{abstract}
ABSTRAK
Stasiun Pengisian Bahan Bakar Umum (SPBU) sementara ini masih belum bisa diakses oleh pengguna secara real-time. Sebuah sistem monitoring level BBM secara realtime diperlukan untuk memenuhi kebutuhan pelanggan atas kebutuhan $B B M$ sehingga dapat menentukan alternatif SPBU lain jika ternyata SPBU terdekat kehabisan stok pada salah satu atau keseluruhan jenis BBM.

Teknologi Augmented Reality (AR) memungkinkan pengguna dengan mudah mencari informasi dan lokasi SPBU terdekat. Pemanfaatkan teknologi Augmented Reality (AR) serta sensor GPS yang berinteraksi dengan google maps API, pada perangkat smartphone mampu memberikan informasi secara detail, akurat dan tampak nyata bagi pengguna.
\end{abstract}

Perangkat sensor nirkabel dan kontrol oleh Arduino, mampu memberikan kemudahan dalam pengukuran kondisi stok BBM serta dapat menggantikan proses manual pengukuran tangki penyimpan BBM yang selama ini menggunakan tongkat besi pengukur. Komunikasi data jarak jauh dan uji coba tingkat akurasi data menunjukkan bahwa sistem monitoring mampu memberikan informasi akurat secara real-time.

Kata Kunci: Sistem monitoring, SPBU, Augmented-reality, real-time, Arduino.

\section{AUGMENTED-REALITY MONITORING SYSTEM ON GAS STATION}

\section{ABSTRACT}

Gas stations information are still not accessible to the user in real-time. A fuel level monitoring system in real time is noteworthy to meet customer needs. So, people can determine other alternative fuel stations if the nearest station is out of stock on one or all of the fuel types.

Augmented Reality (AR) allows users to easily search for informations and the location of the nearest gas station. This research apply wireless sensor network technology and Augmented Reality (AR) by using GPS sensors that interact with google maps API, wireless sensor and controlled by Arduino. The system is also able to replace the manual process of measuring fuel storage tanks. The result showed that the monitoring system-App is able to provide accurate information in real-time.

Keywords: Monitoring system, gas station, Augmented-reality, real-time, Arduino. 


\section{PENDAHULUAN}

Tangki penyimpan bahan bakar di setiap SPBU umumnya berupa bak penampung yang berada di bawah permukaan tanah. Berdasarkan survei yang telah dilakukan di beberapa SPBU di kota surabaya, pemeriksaan volume ketersediaan bahan bakar di dalam tangki SPBU umumnya dilakukan dengan mengukur ketinggian Bahan bakar Minyak (BBM) yang tersedia di dalam tangki penyimpan secara manual, yaitu dengan menggunakan meteran tongkat atau galah panjang sehingga akurasi pengukuran tidak terjaga, yaitu akibat terjadinya kesalahan paralaks saat pengukuran.

Sistem Monitoring diperlukan untuk memonitoring stok bahan bakar minyak di SPBU. Penggunaan teknologi wireless sensor network memungkinkan pengotrolan atau pemantuan stok SPBU dapat pula dilakukan dari jarak jauh dengan kelebihan fleksibilitas melalui komunikasi jarak jauh secara realtime.

Penerapan teknologi Augmented Reality (AR) dapat memberikan visualisasi yang lebih menarik serta memungkinkan pengguna dapat berinteraksi secara langsung dan memvisualisasikan obyek SPBU, sehingga pengalaman pengguna dalam penggunaan aplikasi semakin terpuaskan.

\section{METODE PENELITIAN}

Penelitian sebelumnya telah dilakukan oleh Tony Wijaya yang berjudul "Rancang bangun aplikasi Augmented Reality untuk penentuan rute dan jarak lokasi fasilitas kesehatan berbasis android" Penelitian tersebut merancang aplikasi yang dikembangkan memanfatkan teknologi AR, Maps dan Google Maps API. Aplikasi yang dibuat memiliki respon positif bagi pengguna dengan jenjang usia 17>25th. Aplikasi mampu memuaskan pengguna dalam pemberian informasi, jarak dan rute fasilitas kesehatan terdekat.

Penelitian yang di lakukan oleh Ilfin Ardini pada paper yang berjudul "Aplikasi telemonitoring obyek wisata menggunakan Augmented Reality berbasis lokasi" penelitian tersebut Aplikasi telemonitoring obyek wisata menggunakan Augmented Reality (AR) berbasis lokasi ini dibuat untuk mempermudah wisatawan dalam mencari informasi suatu obyek wisata dan dapat memantau tanpa harus mendatangi obyek wisata tersebut. Dengan memanfaatkan teknologi AR melalui penggunaan kamera, GPS, Kompas, dan Akselerometer pada perangkat android aplikasi ini dapat memberikan informasi secara detail, akurat dan tampak nyata bagi pengguna.

Pada penelitian ini AR library

Mixare (Mix Augmented Reality Engine) digunakan untuk memvisualisasikan pencarian SPBU terdekat, Google maps API digunakan untuk penentuan rute menuju SPBU yang dipilih. Sensor ultrasonik dan Arduino digunakan untuk pengukuran level stok BBM pada SPBU. Ethernet shield dengan ethernet chip Wiznet W5100 digunakan dalam menulis program agar arduino board dapat terhubung ke jaringan komputer sehingga data pengukuran tangki BBM dapat dikirim ke server.

Sensor untuk akselerometer
digunakan deteksi
orientasi landscape atau vertical
smartphone pengguna sehingga
tampilan icon-icon dapat tetap terlihat
di depan pengguna walaupun dalam
orientasi yang berbeda-beda.
Koordinat SPBU (latitude dan
longitude) digunakan sebagai proses


masukan pada aplikasi. Selanjutnya program akan merepresentasikan koordinat tersebut dalam bentuk ikon yang nantinya dapat memberikan informasi SPBU yang berada Surabaya kepada pengguna.

Gambar 1 merupakan diagram usecase yang menggambarkan interaksi antara pengguna dengan sistem yang dirancang berdasarkan fungsionalitas yang diberikan sistem.

1. Pengguna dapat mencari letak pom bensin (SPBU) yang terdekat dengan posisinya melalui tampilan Maps.

2. Pengguna mendapatkan informasi lengkap mengenai lokasi SPBU

3. Pengguna dapat mengetahui lokasi keberadaannya melalui Maps.

4. Pengguna dapat mencari petunjuk arah menuju lokasi SPBU

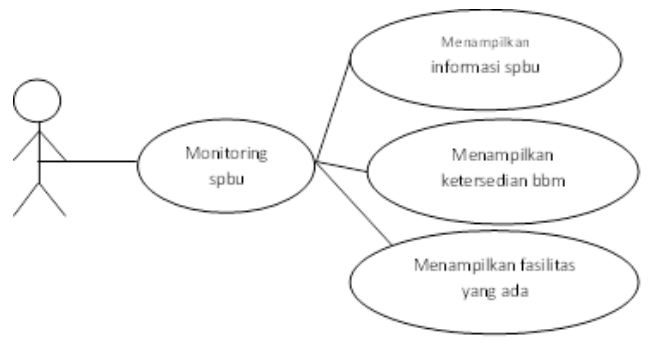

Gambar 1. Usecase Diagram
Acitvity diagram aplikasi, terdapat lima pilihan yaitu, menu ARSPBU, peta SPBU, telemonitoring, simulasi, tentang, pengaturan, keluar. Penjelasan Acitvity diagram Gambar 2 adalah sebagai berikut :

1. Menu AR SPBU : Proses Augmented Reality (AR) pada kamera yang akan menampilkan ikon marker SPBU berserta informasinya.

2. Menu PetaSPBU : Menu ini menampilkan peta, marker lokasi SPBU dan marker posisi pengguna berdasarkan sistem GPS.

3. Menu Telemonitoring SPBU : Berisi informasi SPBU berupa No.Id, alamat, nomer telepon, dan ketersediaan BBM.

4. Menu Tentang : Menjelaskan tentang kotak dialog dengan berisikan informasi mengenai aplikasi.

5. Menu Pengaturan : Menu ini menampilkan proses pengecekan terhadap uesr, GPS, Paket data dan koneksi wifi.

6. Menu Simulasi : Menu ini menampilkan proses simulasi monitoring BBM di SPBU secara realtime.

7. Menu Keluar : Memberikan pilihan bagi pengguna apakah ingin keluar dari aplikasi atau tidak.

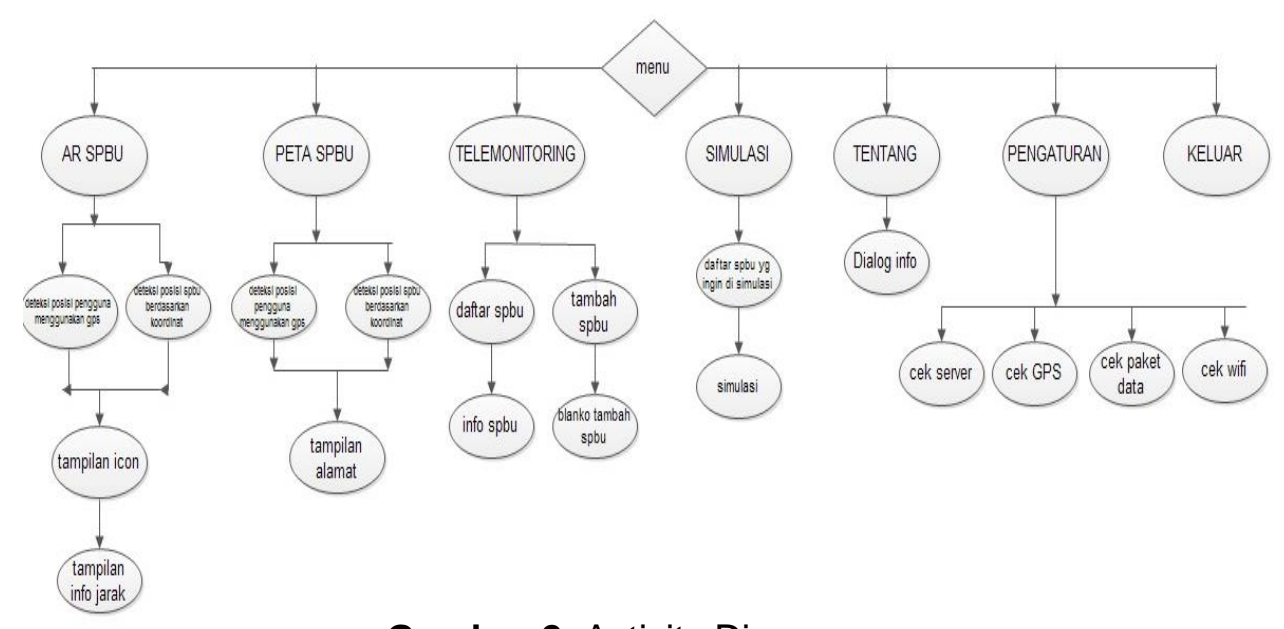

Gambar 2. Activity Diagram 


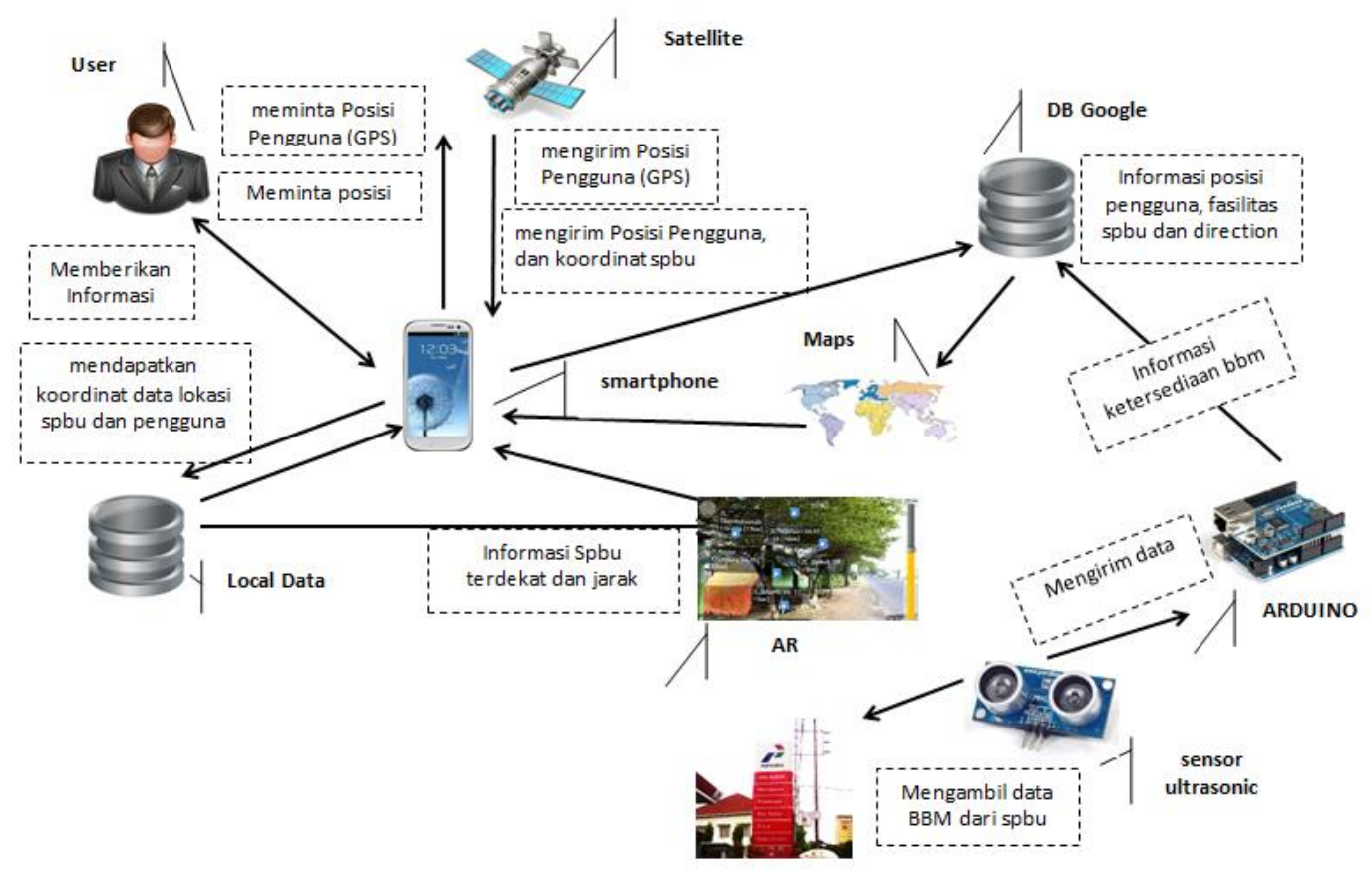

Gambar 3. Prototype sistem

Gambaran prinsip kerja sistem yang dibangun seperti pada gambar 3 , adalah sebagai berikut:

1. Pada saat aplikasi di jalankan perangkat android akan meminta informasi lokasi pengguna berdasarkan latitude, longitude pengguna ke satellite menggunakan GPS.

2. Setelah itu satellite akan memberikan informasi lokasi tempat pengguna berada berdasarkan latitude, longitude melalui perangkat android.

3. Pengguna meminta lokasi berdasarkan latitude, longitude lokasi SPBU terdekat melalui local data pada perangkat.

4. Local data mengirimkan lokasi berdasarkan latitude dan longitude SPBU ke perangkat.

5. Perhitungan koordinat lokasi pengguna dan local data SPBU untuk mendapatkan jarak ke lokasi terdekat SPBU

6. Mobile smartphone android akan menampilkan lokasi SPBU jarak dan rute terdekat, serta lokasi pengguna

kepada perangkat melalui Maps dan menampilkan informasi SPBU terdekat dengan menggunakan Augmented Reality yang memungkinkan pengguna untuk berinteraksi dengan dunia nyata melalui kamera pada perangkat android dan ikon SPBU akan terlihat pada camera berdasarkan jarak antara latitude dan longitude pengguna dan lokasi SPBU terdekat.

7. Proses permintaan lokasi pengguna berdasarkan latitude dan longitude dari satellite, dan pengiriman posisi pengguna kepada Google dilakukan secara terus menerus menggunakan GPS untuk memperbaharui posisi pengguna, hingga nantinya dapat menentukan rute dan jarak tempuh antara pengguna dan SPBU terdekat disekitarnya. 
Tabel 1. Data SPBU

\begin{tabular}{|c|c|c|c|c|c|c|}
\hline \multirow{2}{*}{ No } & \multicolumn{4}{|c|}{ DATA SPBU } & \multicolumn{2}{|c|}{ DATA POSISI SPBU } \\
\hline & ID SPBU & $\begin{array}{l}\text { NAMA } \\
\text { SPBU }\end{array}$ & ALAMAT SPBU & NO.TELP & LATITUDE & LONGITUDE \\
\hline 1 & 54.601 .03 & $\begin{array}{c}\text { SPBU } \\
54.601 .03\end{array}$ & $\begin{array}{c}\text { J1. Kapas Krampung } \\
\text { No. } 99\end{array}$ & $(031) 3714097$ & -7.250102 & 112.76468 \\
\hline 2 & 54.601 .06 & $\begin{array}{c}\text { SPBU } \\
54.601 .06\end{array}$ & $\begin{array}{c}\text { J1. Dharmahusada } \\
114-116\end{array}$ & (031) 500000 & -7.266815 & 112.768737 \\
\hline 3 & 54.601 .46 & $\begin{array}{c}\text { SPBU } \\
54.601 .46\end{array}$ & $\begin{array}{l}\text { Jl. Arief Rachman } \\
\text { Hakim No. } 150\end{array}$ & $(031) 5999951$ & -7.290013 & 112.783955 \\
\hline 4 & 54.601 .79 & $\begin{array}{c}\text { SPBU } \\
54.601 .79\end{array}$ & $\begin{array}{l}\text { J1. Kayon-Embong } \\
\text { Kemiri No. } 48\end{array}$ & (031) 500000 & -7.269238 & 112.747013 \\
\hline 5 & 54.602 .48 & $\begin{array}{c}\text { SPBU } \\
54.602 .48\end{array}$ & $\begin{array}{c}\text { J1. jagir wonokromo } \\
\text { no.362 }\end{array}$ & $(031) 8410025$ & -7.3061176 & 112.7607119 \\
\hline 6 & 54.601 .81 & $\begin{array}{c}\text { SPBU } \\
54.601 .81 \\
\end{array}$ & J1. Dinoyo No. 125 & (031) 500000 & -7.286123 & 112.745503 \\
\hline 7 & 54.601 .83 & $\begin{array}{c}\text { SPBU } \\
54.601 .8\end{array}$ & J1. Demak 158 & $(031) 5466103$ & -7.248389 & 112.721298 \\
\hline 8 & 54.601 .92 & $\begin{array}{c}\text { SPBU } \\
54.601 .92\end{array}$ & $\begin{array}{l}\text { J1. Tegalsari No. 43- } \\
45\end{array}$ & (031) 500000 & -7.265636 & 112.737708 \\
\hline 9 & 54.601 .95 & $\begin{array}{c}\text { SPBU } \\
54.601 .95 \\
\end{array}$ & JL. Jakarta, No. 3 & (031) 500000 & -7.222705 & 112.736965 \\
\hline 10 & 54.601 .99 & $\begin{array}{c}\text { SPBU } \\
54.601 .99\end{array}$ & $\begin{array}{l}\text { J1. Raya Rungkut } \\
\text { Mapan 30-32 }\end{array}$ & (031) 8709661 & -7.334688 & 112.775871 \\
\hline 11 & 54.602 .13 & $\begin{array}{c}\text { SPBU } \\
54.602 .13\end{array}$ & J1. Mayjen Sungkono & (031) 500000 & -7.291981 & 112.723928 \\
\hline 12 & 54.602 .68 & $\begin{array}{c}\text { SPBU } \\
54.602 .68\end{array}$ & J1. Joyoboyo No. 53 & (031) 500000 & -7.296734 & 112.733873 \\
\hline 13 & 54.602 .69 & $\begin{array}{c}\text { SPBU } \\
54.602 .69\end{array}$ & J1. Klampis Jaya & (031) 5941160 & -7.284483 & 112.778583 \\
\hline 14 & 54.602 .72 & $\begin{array}{c}\text { SPBU } \\
54.602 .72\end{array}$ & J1. Lontar 123 & (031) 7533803 & -7.284902 & 112.675711 \\
\hline 15 & 54.601 .66 & $\begin{array}{c}\text { SPBU } \\
54.601 .66\end{array}$ & J1. Raya Margodadi & (031) 500000 & -7.247823 & 112.7251511 \\
\hline
\end{tabular}

8. Proses sensor mengambil data dari SPBU dan mengirimkan ke arduino setelah itu arduino mengirimkan data yang dikirim oleh sensor ke database server

\section{HASIL DAN PEMBAHASAN}

Implementasi data yang diperoleh dari hasil SPBU yang ada di kota Surabaya. Di dalam membangun aplikasi sistem monitoring SPBU ini diperoleh data SPBU yang ada di Surabaya. Data SPBU tersebut meliputi Id SPBU, alamat, latitude, longitude, nomor telepon, dan deskripsinya hal ini di tunjukan pada Tabel 1.

\section{UJI FUNGSIONALITAS}

Monitoring controller arduino menggunakan port 37. Data yang didapat dari sensor dikirimkan ke database server.

\section{Uji Hasil Augmented Reality (AR)}

Pengujian dilakukan pada menu AR SPBU untuk pencarian lokasi SPBU dengan menggunakan kamera. Menu ini menampilkan lokasi SPBU terdekat di sekitar dengan menentukan jarak tempuhnya. Poin of interest ditunjukkan oleh marker yang muncul selanjutnya untuk menapatkan detil informasi obyek dilakukan dengan meng-klik ikon marker tersebut dan kemudian akan menampilkan informasi detil SPBU yang sudah dipilih tersebut. Semua proses 


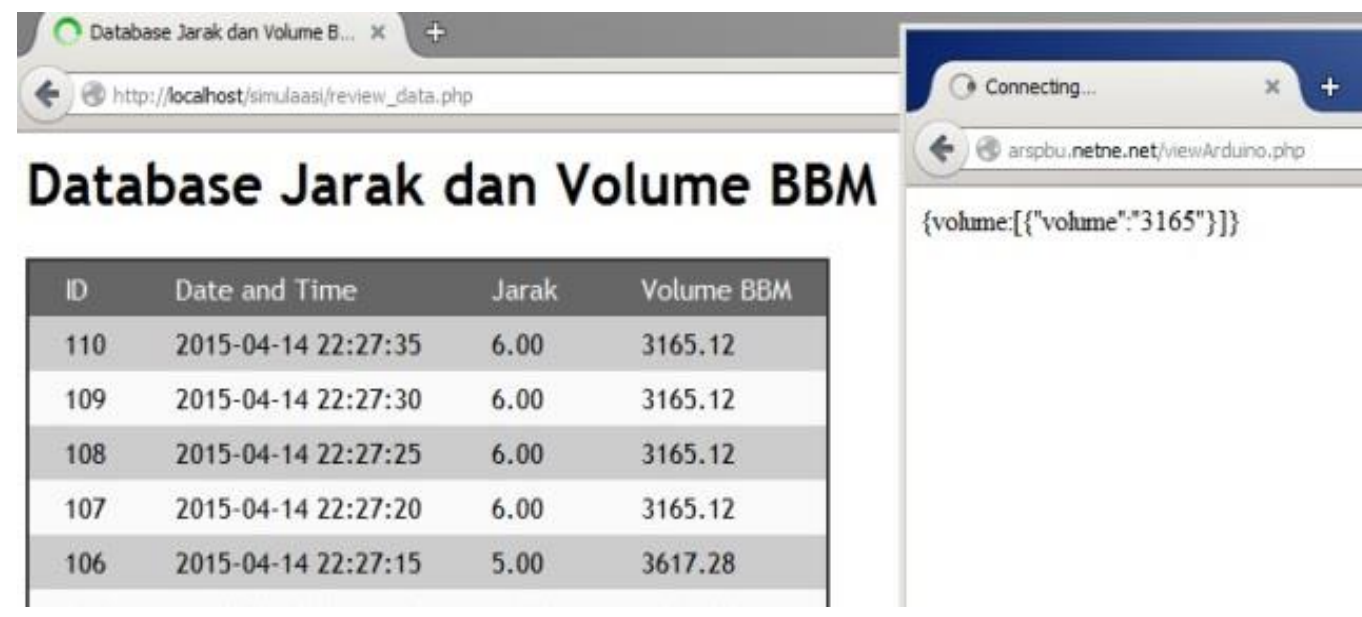

Gambar 4. Contoh hasil pengambilan data sensor

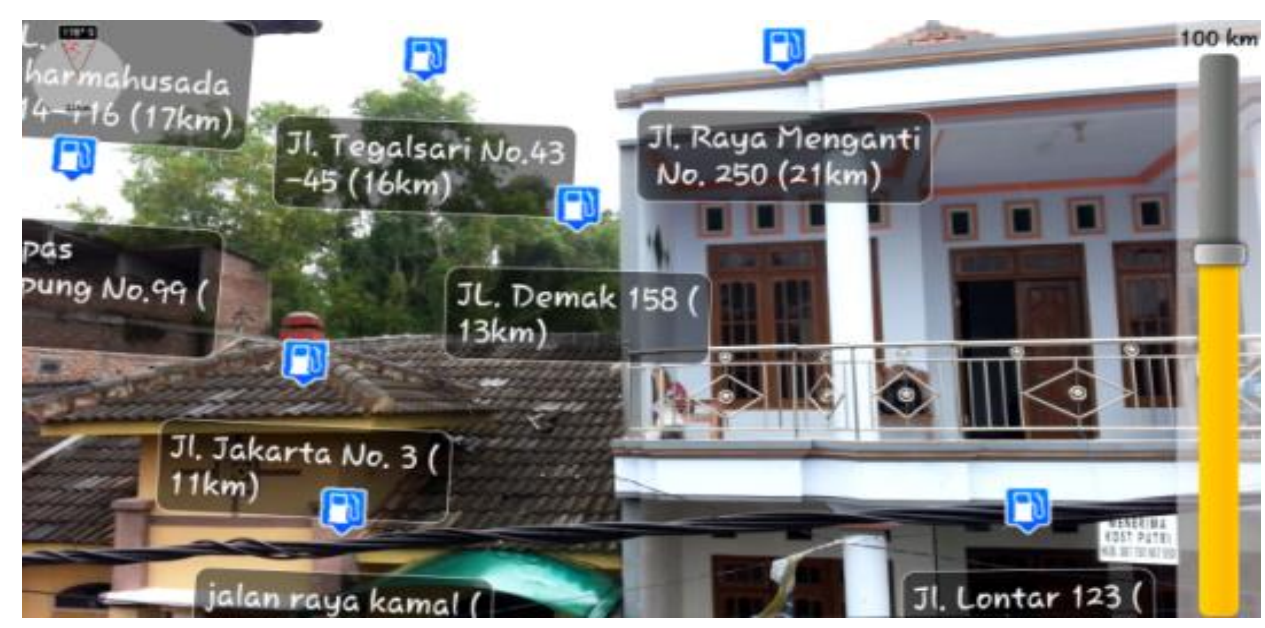

Gambar 5. Uji Coba AR Resolusi HD

tersebut melibatkan sensor GPS, kompas, akselerometer dan akses koneksi internet.

Selanjutnya dilakukan uji untuk menu detil SPBU

a) Detail Informasi SPBU

Tampak pada Gambar 6 bahwa tampilan detail informasi SPBU pada perangkat android dengan jenis resolusi layar HD sudah sesuai dan tidak ada masalah.

b) Form tambah SPBU

Pada Gambar 7 tampak bahwa tampilan menu tambah SPBU pada perangkat android dengan jenis resolusi layar HD tidak terdapat masalah dan sesuai.

Pada Gambar 8 tampak bahwa tampilan Identitas SPBU pada perangkat android dengan jenis resolusi layar HD tidak terdapat masalah dan sudah sesuai.

c) Foto dan fasilitas SPBU

Pada Gambar 9 tampak bahwa tampilan identitas SPBU pada perangkat android dengan jenis resolusi layar HD tidak terdapat masalah dan sudah sesuai 


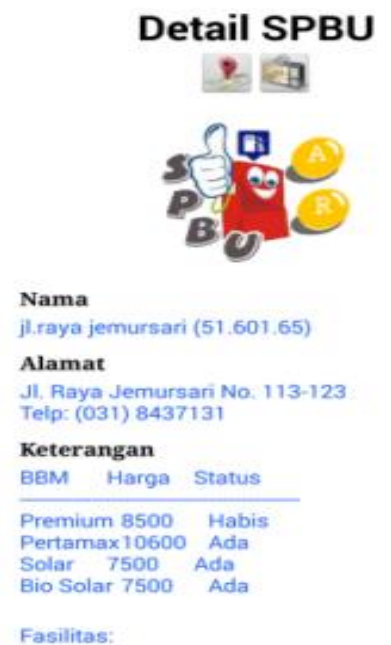

6s:

Gambar 6. Detil SPBU pada Resolusi HD

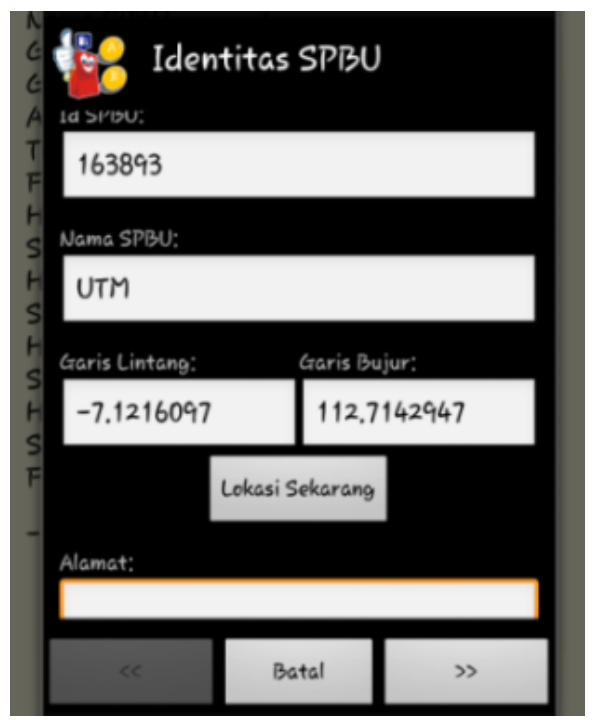

Gambar 8. Identitas SPBU pada Jenis Resolusi HD

d) Jenis-jenis BBM di SPBU

Pada Gambar 10 tampak bahwa tampilan Jenis-jenis BBM di SPBU pada perangkat android dengan jenis resolusi layar HD tidak terdapat masalah dan sudah sesuai.

\section{SIMULASI SPBU}

Pada Gambar 11 tampak bahwa tampilan Simulasi penujuk arah SPBU berbasis google map
Blanko Tambah SPBU

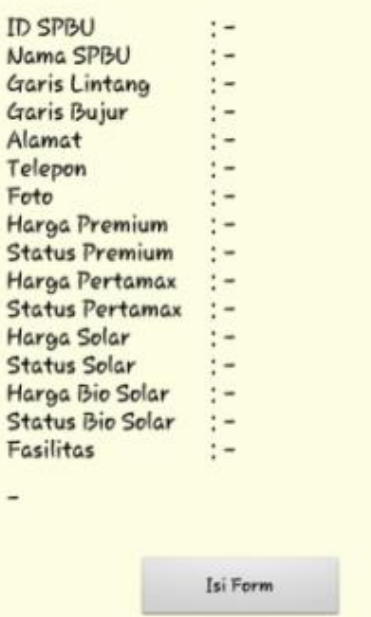

Gambar 7. Tambah SPBU

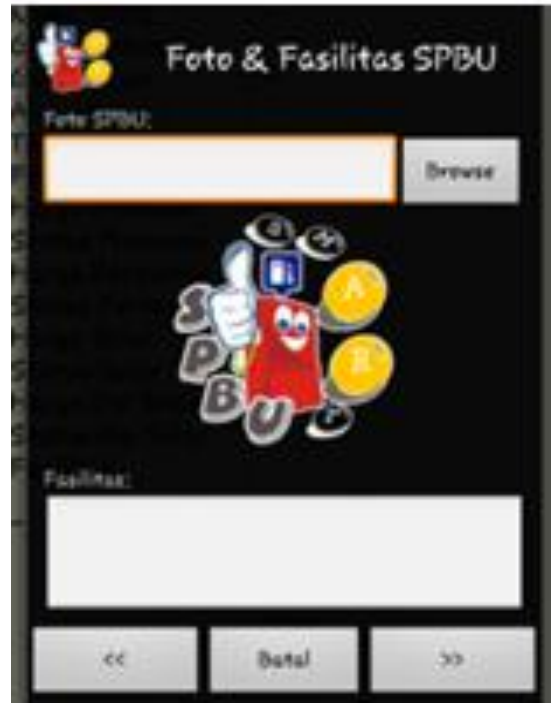

Gambar 9. Identitas SPBU pada Jenis Resolusi HD

pada perangkat android dengan jenis resolusi layar HD tidak terdapat masalah dan sudah sesuai.

\section{SIMPULAN}

Dari serangkaian pengujian didapatkan kesimpulan bahwa:

1. Akses internet diperlukan untuk menampilkan detil SPBU 


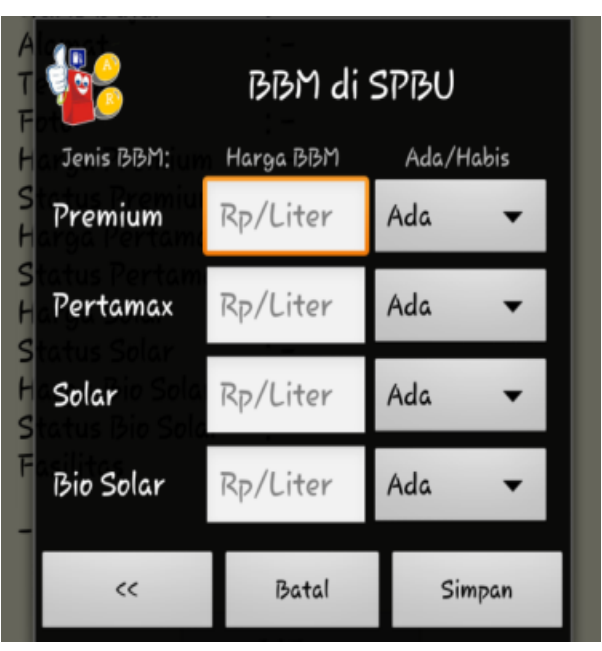

Gambar 10. Jenis BBM di SPBU pada Jenis Resolusi HD

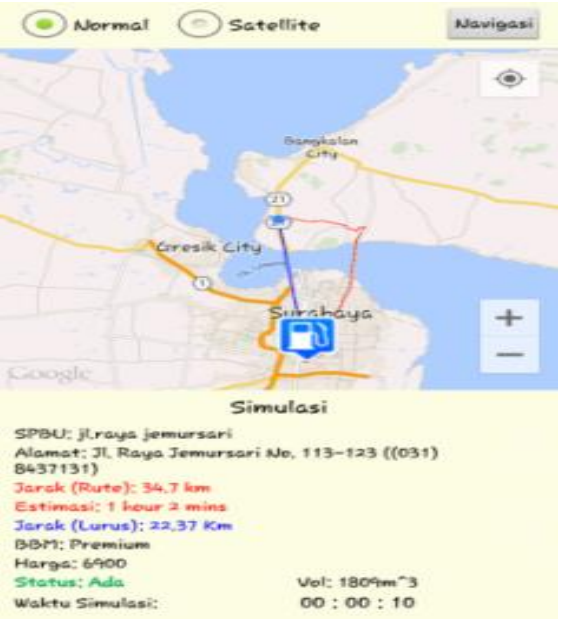

Gambar 11. Simulasi SPBU pada Jenis Resolusi HD

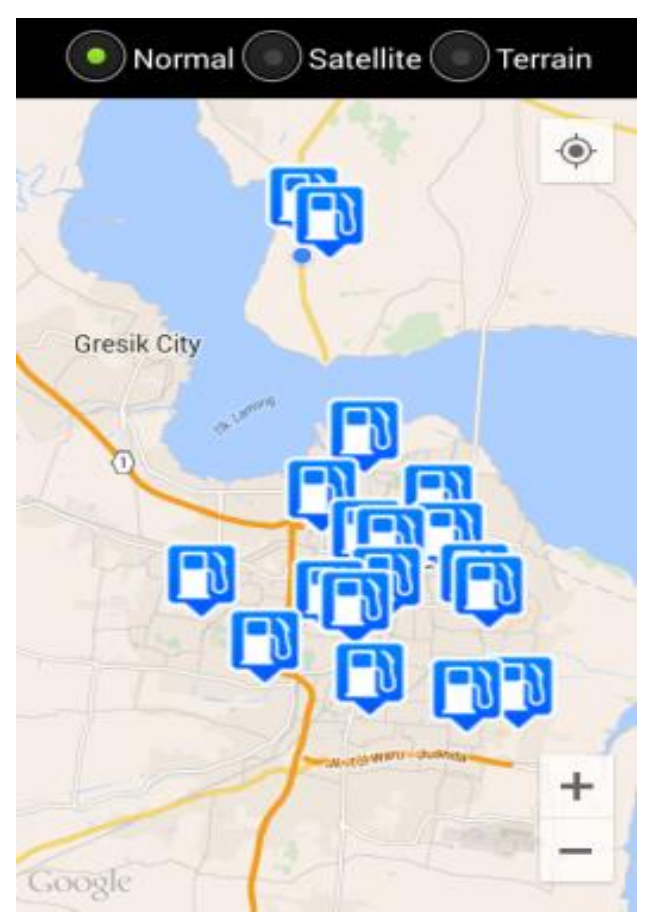

Gambar 12. Simulasi lokasi SPBU

sehingga perngkat harus memiliki akses internet setara 3G.

2. Aplikasi AR berbasis lokasi berjalan dengan baik dengan tersedianya sensor kompas, akselerometer, jarak maksimal tentukan yaitu $100 \mathrm{~km}$.
3. Daftar SPBU dan detail informasi SPBU dapat ditampilkan dengan baik

4. Berdasarkan pengujian pada masing-masing resolusi hanya pada resolusi layar QVGA yang mengalami gangguan. 


\section{DAFTAR PUSTAKA}

Hendrianto, D., dan Mazharuddin, A. (2011). Implementasi AugmentedReality Memanfaatkan Sensor Akselerometer, Kompas, dan GPS Pada Penentuan Lokasi Masjid Berbasis Android. Tugas Akhir Prodi Teknik Informatika ITS.

Ilfin Ardini. (2014). Telemonitoring obyek wisata menggunakan augmented reality berbasis lokasi. Tugas Akhir Prodi informatika Universitas Trunojoyo Madura
Prastowo.(2012). Perancangan Aplikasi Pencari Masjid Menggunakan Global Positioning System (GPS) pada Platform Android. Tugas Akhir Prodi Teknik Elektro UNDIP Semarang.

Tony Wijaya. (2013), Rancang bangun aplikasi augmented reality untuk penentuan rute dan jarak lokasi fasilitas kesehatan berbasis android. Tugas Akhir Prodi informatika Universitas Trunojoyo 